\title{
DETERMINING THE SIGNIFICANCE OF EXTREME EVENTS IN TEXAS CONSTRUCTION MARKET THROUGH OUTLIER DETECTION OF TEXAS CONSTRUCTION HIRING DATA
}

\author{
Milad Ashtab and Boong Yeol Ryoo ${ }^{1}$ \\ ${ }^{l}$ Ph.D. \\ Texas A \& M University, Francis Hall, Room 317, College Station, Texas 77843-3137, USA
}

\begin{abstract}
The Texas construction market is the second-largest hub inside the U.S. Nearly 750 thousand people are working in different sectors of the Texas construction industry. Although the big picture indicates steady growth in Texas hiring size in the last 30 years, the Texas construction market's volatility has been an issue for construction companies and their hiring plans. Rather than seasonal patterns inherent to construction activities, factors such as economic recessions and crises, tropical hurricanes, and outbreaks of pandemics are potential reasons for fluctuations in construction companies' demand to hire. The impact of each factor on the cities varies due to geographical and demographical diversity inside Texas. This paper focuses on understanding workforce migration behaviors following local disasters because it relies heavily on the local workforce. To determine each factor's significance is to find if they created an anomaly in the dataset after they occurred. This research implemented an outlier detection analysis on Texas cities and compared the resulting outlier dates with the timeline of Texas's extreme events in the last 30 years. The results show that economic crises with national scales such as the dot-com bubble at the start of the century and the 2008 economic crisis mostly affected four major cities (Austin, Houston, Dallas/Fort Worth, and San Antonio) of Texas. Multi-state local disasters such as hurricane Harvey impacted both major cities and their satellite cities, suggesting the migration of the workforce to the disaster-areas. The research found that low population cities have been affected by local disasters.
\end{abstract}

\section{KEYWORDS}

Post-Disaster, Construction Hiring, Workforce Migration, Extreme Events Analysis, Outlier Detection

\section{INTRODUCTION}

The construction industry is still one of the most labor-intensive industries, while technological advances move other industrial sectors toward automation (Dainty et al., 2007). The construction market also provides relatively high-paying jobs for workforces with average skill levels (Shrestha et al., 2020). Meanwhile, the construction sector added a 3 to 5 percent value to the United States' total GDP (Gross Domestic Product) in the last 30 years. The Texas construction market is the second-largest hub for construction hiring, with nearly 750,000 hired people falling only behind California (U.S. Bureau of Economic Analysis, 2020). Although the general trend shows steady growth in hiring for the last 20 years, the market's volatility has been a significant problem. The construction industry's cyclical behavior provokes many recessions after periodic expansion and vise versa, which eventuate fluctuations in hiring rates (Hadi, 2011). The example of the 2008 economic crisis after a relative boom in the construction market in 2005 and 2006 and dominos of layoffs in construction companies indicates the problem's criticality (Chang et al., 2009). Various other extreme events like political turmoil, hurricanes, and pandemics can also impact the Texas construction market's volatility. Predicting the future of construction economic variables through the application of time-series models and machine learning could be a possible solution for reducing uncertainty in the Texas construction market. However, the multiplicity and diversity of such events and the number of economic factors affecting hiring are high and would eventuate complex time-series and machine learning models. The paper aims at finding potential synchronicity between natural disasters, extreme socio-economic, and political events with outlier points in the Texas construction hiring data. 


\section{LITERATURE REVIEW}

Previous related works compromise three main domains: the first task is to investigate the scholarly works focusing on reducing construction outputs' uncertainty, specifically employment, spending, and Construction Cost Index (CCI). The second task includes works that are trying to predict the future of construction. The last task is quantify the effect of extreme events on construction market output. The following predictive statistical methods had been promising tools in determining future values of varying construction outputs. Autoregressive (AR) and Autoregressive Integrated Moving Average (ARIMA) models for time-series had been used to predict multi-family housing prices (Fullerton Jr et al., 2001), future price and work item rates in Singapore (Hua and Pin, 2000), material costs in the post-disaster situation (Khodahemmati and Shahandashti, 2020). The vector and error correction method is also applied to forecast CCI and National Highway CCI using monthly data (Ashuri et al., 2012) and determine economic growth and construction demand (Jiang and Liu, 2011). Ahmadi and Shahandashti (2020) also used panel spatial data to determine the workforce demand surge in Texas's post-disaster situations. Fan et al. (2010) evaluated Box-Jenkins model's capability to estimate recovery time in post-disaster construction markets. Cao and Ashuri (2020) applied the ARIMA models to the monthly CCI values and compared their performance with Long Short Term Memories (LSTM).

\section{METHODOLOGY}

The paper has four main steps: (1) Data gathering, (2) Decomposing time-series data, (3) Outlier detection, and (4) Mapping outliers and extreme events synchrony points. The first step has two components. The initial data used to create a timeline of extreme events consisting of extreme events' date, damage levels and impacted Texas areas. A time-series analysis was performed for construction hiring using the construction hiring data in Texas from 1990 to 2020 from the U.S. Bureau of Labor and Statistics (U.S. Bureau of Labor Statistics, 2020). The second step is to decompose the time series data. Each time-series can be decomposed as follows:

$$
y_{t}=S_{t}+T_{t}+R_{t}
$$

Where $S_{t}$ is the seasonal component of data and $T_{t}$ represents the trend for the given timespan, and $R_{t}$ represents the residual of the data. Anomaly detection is performed on the dataset to identify outlier points. The outliers, which are specific periods reconciled with the timeline developed based on significant natural disasters, economic and political events in the State of Texas. The anomaly detection of time series focuses on $R_{t}$ and its fluctuations from the mean of residuals. Its null hypothesis that any given point is not an outlier. To determine which residual is an anomaly in the dataset, upper and lower bands should be defined based on the desired confidence level. Points with values more than the upper and lower bands would reject the null hypothesis and be considered an anomaly in the dataset. The higher confidence level eventuates in more distance from residuals for upper and lower values, which would detect less but more reliable outliers

\section{DATA ANALYSIS}

Anomaly detection was performed on the Texas metropolitan area's construction hiring time series. Figure 1 shows an example data decomposition for the City of Houston that shows finding outlier points. The same process is applied for decomposing the hiring data for four major economic areas in Texas. Tables 1 to 4 show anomalies such as hiring trend, seasonality, residuals, an upper and lower value for outlier detection of data in the major areas of Texas. A prevalent anomaly span for the cities occurs between 2008 and 2010, which is concurrent to the economic crisis. For example, significant metropolitan areas such as Dallas/Fort Worth, Houston, and Austin also have outlier points between 2000 and 2001, contemporary to the dot-com crisis. Hurricanes and tropical storms contributed outlier points on the local scale. Corpus Christi and Beaumont are the cities affected by Hurricane Harvey, and the effect can also be seen in outlier points for incremental hiring for Texas. 


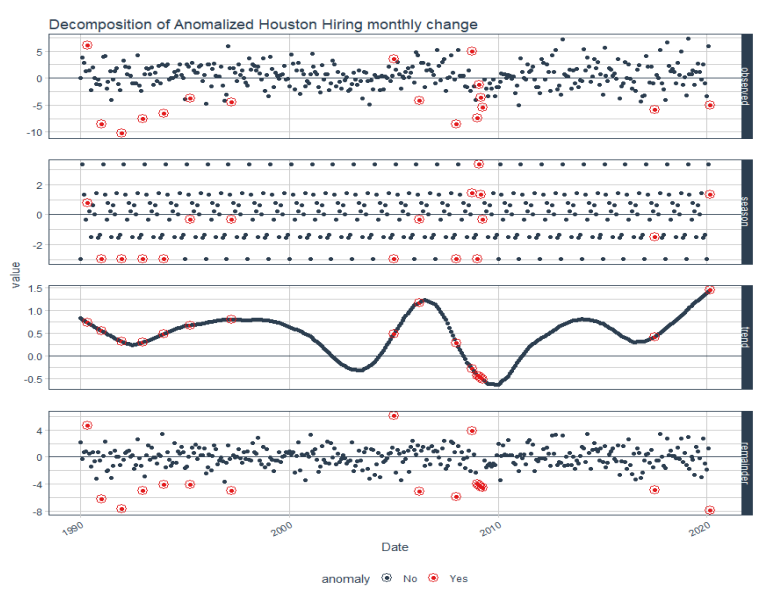

Figure 1. Decomposition of Houston Hiring monthly Change

Table 1. Observed Anomaly Points Houston Hiring Time Series

\begin{tabular}{|c|c|c|c|c|c|c|c|}
\hline Date & Observed & Season & Trend & Remainder & Lower Band & Higher Band & Anomaly \\
\hline $5 / 1 / 1990$ & 6.100 & 0.784 & 0.735 & 4.581 & -4.003 & 3.794 & Yes \\
\hline 1/1/1991 & -8.600 & -2.971 & 0.556 & -6.185 & -4.003 & 3.794 & Yes \\
\hline $1 / 1 / 1992$ & -10.300 & -2.971 & 0.317 & -7.647 & -4.003 & 3.794 & Yes \\
\hline $1 / 1 / 1993$ & -7.600 & -2.971 & 0.300 & -4.930 & -4.003 & 3.794 & Yes \\
\hline $1 / 1 / 1994$ & -6.600 & -2.971 & 0.497 & -4.126 & -4.003 & 3.794 & Yes \\
\hline 4/1/1995 & -3.700 & -0.344 & 0.679 & -4.035 & -4.003 & 3.794 & Yes \\
\hline 4/1/1997 & -4.500 & -0.344 & 0.805 & -4.961 & -4.003 & 3.794 & Yes \\
\hline $1 / 1 / 2005$ & 3.600 & -2.971 & 0.494 & 6.077 & -4.003 & 3.794 & Yes \\
\hline $4 / 1 / 2006$ & -4.200 & -0.344 & 1.179 & -5.035 & -4.003 & 3.794 & Yes \\
\hline $1 / 1 / 2008$ & -8.600 & -2.971 & 0.282 & -5.912 & -4.003 & 3.794 & Yes \\
\hline $10 / 1 / 2008$ & 5.000 & 1.424 & -0.281 & 3.857 & -4.003 & 3.794 & Yes \\
\hline $1 / 1 / 2009$ & -7.400 & -2.971 & -0.423 & -4.007 & -4.003 & 3.794 & Yes \\
\hline
\end{tabular}

Table 2. Observed Anomaly Points in Dallas/Fort Worth Hiring Time Series

\begin{tabular}{llllllll}
\hline Date & Observed & Season & Trend & Remainder & Lower Band & Higher Band & Anomaly \\
\hline $1 / 1 / 1990$ & 0.000 & -2.528 & -0.253 & 2.781 & -1.965 & 1.884 & Yes \\
\hline $7 / 1 / 2001$ & -2.200 & 0.180 & -0.043 & -2.337 & -1.965 & 1.884 & Yes \\
\hline $10 / 1 / 2001$ & -3.300 & -0.809 & -0.114 & -2.377 & -1.965 & 1.884 & Yes \\
\hline $4 / 1 / 2006$ & -0.700 & 0.718 & 0.633 & -2.050 & -1.965 & 1.884 & Yes \\
\hline $7 / 1 / 2006$ & -1.500 & 0.180 & 0.633 & -2.312 & -1.965 & 1.884 & Yes \\
\hline $7 / 1 / 2007$ & -2.000 & 0.180 & 0.312 & -2.492 & -1.965 & 1.884 & Yes \\
\hline $2 / 1 / 2008$ & 2.900 & 0.831 & 0.001 & 2.068 & -1.965 & 1.884 & Yes \\
\hline $1 / 1 / 2009$ & -5.400 & -2.528 & -0.309 & -2.563 & -1.965 & 1.884 & Yes \\
\hline $4 / 1 / 2009$ & -2.100 & 0.718 & -0.338 & -2.480 & -1.965 & 1.884 & Yes \\
\hline $10 / 1 / 2009$ & -3.700 & -0.809 & -0.358 & -2.533 & -1.965 & 1.884 & Yes \\
\hline $3 / 1 / 2015$ & -0.200 & 1.231 & 0.562 & -1.993 & -1.965 & 1.884 & Yes \\
\hline $10 / 1 / 2019$ & 2.000 & -0.809 & 0.734 & 2.074 & -1.965 & 1.884 & Yes
\end{tabular}


Table 3. Observed Anomaly Points in Austin Hiring Time Series

\begin{tabular}{llllllll}
\hline Date & Observed & Season & Trend & Remainder & Lower Band & Higher Band & Anomaly \\
\hline $1 / 1 / 1990$ & 0.000 & -0.869 & -0.034 & 0.903 & -0.761 & 0.761 & Yes \\
\hline $2 / 1 / 1994$ & -0.200 & 0.374 & 0.312 & -0.886 & -0.761 & 0.761 & Yes \\
\hline $3 / 1 / 2000$ & 1.400 & 0.339 & 0.160 & 0.901 & -0.761 & 0.761 & Yes \\
\hline $10 / 1 / 2001$ & -1.000 & -0.140 & -0.075 & -0.785 & -0.761 & 0.761 & Yes \\
\hline $11 / 1 / 2001$ & -1.100 & -0.240 & -0.083 & -0.776 & -0.761 & 0.761 & Yes \\
\hline $1 / 1 / 2003$ & 0.100 & -0.869 & -0.114 & 1.083 & -0.761 & 0.761 & Yes \\
\hline $1 / 1 / 2008$ & -1.900 & -0.869 & -0.026 & -1.005 & -0.761 & 0.761 & Yes \\
\hline $10 / 1 / 2008$ & -1.200 & -0.140 & -0.160 & -0.900 & -0.761 & 0.761 & Yes \\
\hline $4 / 1 / 2010$ & 1.100 & 0.248 & -0.158 & 1.010 & -0.761 & 0.761 & Yes \\
\hline $7 / 1 / 2010$ & 0.800 & 0.092 & -0.118 & 0.825 & -0.761 & 0.761 & Yes \\
\hline $10 / 1 / 2019$ & 1.200 & -0.140 & 0.240 & 1.100 & -0.761 & 0.761 & Yes \\
\hline $11 / 1 / 2019$ & 1.800 & -0.240 & 0.239 & 1.801 & -0.761 & 0.761 & Yes \\
\hline
\end{tabular}

Table 4. Observed Anomaly Points in San Antonio Hiring Time Series

\begin{tabular}{llllllll}
\hline Date & Observed & Season & Trend & Remainder & Lower Band & Higher Band & Anomaly \\
\hline $1 / 1 / 1990$ & 0.000 & -0.869 & -0.034 & 0.903 & -0.761 & 0.761 & Yes \\
\hline $2 / 1 / 1994$ & -0.200 & 0.374 & 0.312 & -0.886 & -0.761 & 0.761 & Yes \\
\hline $3 / 1 / 2000$ & 1.400 & 0.339 & 0.160 & 0.901 & -0.761 & 0.761 & Yes \\
\hline $10 / 1 / 2001$ & -1.000 & -0.140 & -0.075 & -0.785 & -0.761 & 0.761 & Yes \\
\hline $11 / 1 / 2001$ & -1.100 & -0.240 & -0.083 & -0.776 & -0.761 & 0.761 & Yes \\
\hline $1 / 1 / 2003$ & 0.100 & -0.869 & -0.114 & 1.083 & -0.761 & 0.761 & Yes \\
\hline $1 / 1 / 2008$ & -1.900 & -0.869 & -0.026 & -1.005 & -0.761 & 0.761 & Yes \\
\hline $10 / 1 / 2008$ & -1.200 & -0.140 & -0.160 & -0.900 & -0.761 & 0.761 & Yes \\
\hline $4 / 1 / 2010$ & 1.100 & 0.248 & -0.158 & 1.010 & -0.761 & 0.761 & Yes \\
\hline $7 / 1 / 2010$ & 0.800 & 0.092 & -0.118 & 0.825 & -0.761 & 0.761 & Yes \\
\hline $10 / 1 / 2019$ & 1.200 & -0.140 & 0.240 & 1.100 & -0.761 & 0.761 & Yes \\
\hline $11 / 1 / 2019$ & 1.800 & -0.240 & 0.239 & 1.801 & -0.761 & 0.761 & Yes \\
\hline
\end{tabular}

\section{FINDINGS AND CONCLUSION}

This research is conducted as a preliminary step for quantifying extreme events' effect on construction market output. Before developing whether statistical or machine learning methods measure extreme events' impact on construction, the current paper implements an outlier detection model on construction hiring to identify significant trends and pattern shifts in the data. By comparing outliers to the list of extreme events, each event's impact was measured for major metropolitan areas in the State of Texas. The economic downturns in 2008 affected many cities in Texas as there was at least one outlier point in each city between 2008 and 2010. The 2008 economic depression was a national-level crisis, and outliers' dates show that it affected Texas cities in two years. Most anomaly points detected between 2008 and 2010 were lower than expected. For Houston, the outliers were more repetitive, and the period that they appeared in the data was longer than the other major areas. For the smaller cities, the outliers were more likely to happen in the early stages of the crisis, which indicates the more significant impact of the economic crisis on the larger economic area.

The general pattern that indicates the high impacts of the economic crisis on construction markets was also traceable in the Dot-com bubble burst in 1997 and the early 1990' s recessions. Both had similar effects on Dallas/Fort Worth, Austin, and San Antonio, which were major metropolitan areas. The outliers related to 1997 and early 1990' s recessions were different from that of 2008 as some represent an increase in hiring in larger cities and a decrease in smaller cities, which indicates workforce migration from smaller construction markets 
to larger markets, which might be hit by those recessions more significantly. The major cities were strong enough to handle the 1997 and early 1990' 's recessions.

Tropical storms and hurricanes had mostly local effects on the construction market. Outliers in small cities such as Corpus Christi and Beaumont are synchronized with the dates available for hurricanes Ike in 2008, Harvey in 2017, and Chantal in 1989 because the cities were close enough to the damaged cities. The outliers show that larger cities faced a lower employment rate than usual while hit small cities experienced a boom in employment rate followed by a 4-6 month decrease. It indicates another migration pattern that is less stable due to temporary construction opportunities in the damaged areas. Tropical storms and hurricanes had a significant effect on low population cities. To sum up, this paper demonstrates that the level of impact due to extreme events can be used to measure the impact on the construction market and its employment. Based on the extreme event's type and extent, workforce employment rates in economic zones and their satellite cities can be affected.

\section{REFERENCES}

Ahmadi, N. \& Shahandashti, M., 2020. Characterizing Construction Demand Surge Using Spatial Panel Data Models. Natural Hazards Review, 21, 04020008.

Cao, Y. \& Ashuri, B., 2020. Predicting the Volatility of Highway Construction Cost Index Using Long Short-Term Memory. Journal of Management in Engineering, 36, 04020020.

Chang, H.-T., W.U., H.-J. \& Ting, I.-H., 2009. Mining organizational networks for layoff prediction model construction. 2009 International Conference on Advances in Social Network Analysis and Mining, 2009. IEEE, 411-416.

Dainty, A., Grugulis, I. \& Langford, D., 2007. Understanding construction employment: the need for a fresh research agenda. Personnel Review.

Fan, R. Y., N.G., S. T. \& Wong, J. M., 2010. Reliability of the Box-Jenkins model for forecasting construction demand covering times of economic austerity. Construction Management and Economics, 28, 241-254.

Fullerton Jr, T. M., Laaksonen, M. M. \& West, C. T., 2001. Regional multi-family housing start forecast accuracy. International Journal of Forecasting, 17, 171-180.

Hadi, A., 2011. Construction employment peaks before the recession and falls sharply throughout it. Monthly Labor Review, 134, 24-27.

Hua, G. B. \& Pin, T. H. 2000. Forecasting construction industry demand, price and productivity in Singapore: The BoxJenkins approach. Construction Management and Economics, 18, 607-618.

Jiang, H. \& Liu, C., 2011. Forecasting construction demand: a vector error correction model with dummy variables. Construction Management and Economics, 29, 969-979.

Khodahemmati, N. \& Shahandashti, M., 2020. Diagnosis and Quantification of Postdisaster Construction Material Cost Fluctuations. Natural Hazards Review, 21, 04020019.

Shrestha, B. K., Choi, J. O., Shrestha, P. P., Lim, J. \& Nikkhah Manesh, S., 2020. Employment and Wage Distribution Investigation in the Construction Industry by Gender. Journal of Management in Engineering, 36, 06020001.

U.S. Bureau of Economic Analysis., 2020. Value Added by Private Industries: Construction as a Percentage of GDP [VAPGDPC] [Online]. Available: retrieved from FRED, Federal Reserve Bank of St. Louis; https://fred.stlouisfed.org/series/VAPGDPC, [Accessed December 13, 2020].

U.S. Bureau of Labor Statistics., 2020. Hires: Construction [JTS2300HIL] [Online]. Available: retrieved from FRED, Federal Reserve Bank of St. Louis; https://fred.stlouisfed.org/series/JTS2300HIL [Accessed December 13, 2020]. 